\title{
Use of Medium-chain Triglyceride Diets in Children with Malabsorption
}

\author{
F. C. LEYLAND, AUDREY S. FOSBROOKE, JUNE K. LLOYD, M. M. SEGALL, \\ I. TAMIR, R. TOMKINS, and O. H. WOLFF \\ From the Department of Child Health, Institute of Child Health, University of London
}

Medium-chain triglyceride (MCT) contains fatty acids with 8 or 10 carbon atoms and differs from long-chain triglyceride (LCT, containing fatty acids with 12 or more carbon atoms) in its water miscibility, its faster hydrolysis by pancreatic lipase, its ability to enter the intestinal mucosal cell unhydrolyzed and to undergo hydrolysis within the cell, and in the subsequent transport of its fatty acids, which are carried in an albumin complex in the portal blood stream. These properties form the basis for the use of MCT in situations in which the absorption of ordinary dietary fat (predominantly LCT) is impaired, and MCT diets have been described in the treatment of various malabsorptive states: in obstructive jaundice (Burke and Danks, 1966; Linscheer et al., 1966) and cystic fibrosis (Kuo and Huang, 1965; Anderson, 1968), where there is defective intraluminar digestion; in tropical sprue (Cancio and MenéndezCorrada, 1964) and after intestinal resection (Zurier et al., 1966; Winawer et al., 1966; Burke and Anderson, 1967), where the absorptive area is decreased; in a- $\beta$-lipoproteinaemia (Isselbacher et al., 1964; Lloyd, 1968), where chylomicrons cannot be formed; and in intestinal lymphangiectasia (Holt, 1964; Holt, Hashim, and Van Itallie, 1965; Yssing, Jensen, and Jarnum, 1967; Poley et al., 1967), where chyle flow is obstructed. Because of its calorific value of $8.3 \mathrm{cal} . / \mathrm{g}$. (Kaunitz et al., 1958), MCT is likely to be particularly useful in the treatment of malabsorption in childhood when growth failure is often a problem. Encouraging results in this respect have been reported in cystic fibrosis (Kuo and Huang, 1965; Anderson, 1968), in liver disease (Burke and Danks, 1966), and after intestinal resection (Burke and Anderson, 1967).

We describe our experience with MCT in the

Received August 30, 1968. treatment of 13 children with malabsorption due to various causes.

\section{Patients and Methods}

Patients. Three children had obstructive jaundice, 3 had pancreatic insufficiency ( 2 associated with neutropenia and 1 with enterocolitis), 2 had a- $\beta$-lipoproteinaemia, and 5 had intestinal lymphangiectasia. The clinical details are summarized in Appendix I.

Diets. The daily intake of LCT was reduced; the amount allowed depended on the age of the child and the severity of malabsorption, and varied between $1 \mathrm{~g}$. and $28 \mathrm{~g}$. (Table I). Some children were given a low LCT diet before the introduction of MCT; in others the dietary changes were made simultaneously. In all patients MCT was introduced gradually over a period of about one week. The final amount of MCT was 20-70 g. per day and the total quantity of fat (MCT + LCT) was adjusted to provide about $40 \%$ of total calories. The fatty acid composition of the various MCT products, as determined in our laboratory, is given in Table II. For 12 children the products made by the Mead Johnson Co. were used; the remaining patient (Case 5) was given MCT oil made by Unilever Ltd. Details of the MCT diet are described by Francis and Dixon (1969). The diets have been continued for 5-36 months.

Analytical methods. The standard van de Kamer method for faecal fat analysis (van de Kamer, ten Bokkel Huinink, and Weyers, 1949) is unsuitable for patients receiving MCT, because medium-chain fatty acids are soluble in water, and because a titrimetric method is inappropriate for the determination of a mixture of fatty acids of widely differing molecular weights. We obtained a recovery of only $22 \%$ when MCT oil (Mead Johnson) was added to a faecal homogenate before saponification and extraction according to the method of van de Kamer but using a final gravimetric estimation. We have, therefore, developed a method for faecal fat estimation using triple extraction with petroleum ether and gravimetric determination 
TABLE I

Faecal Fat in Children on LCT and MCT Diets

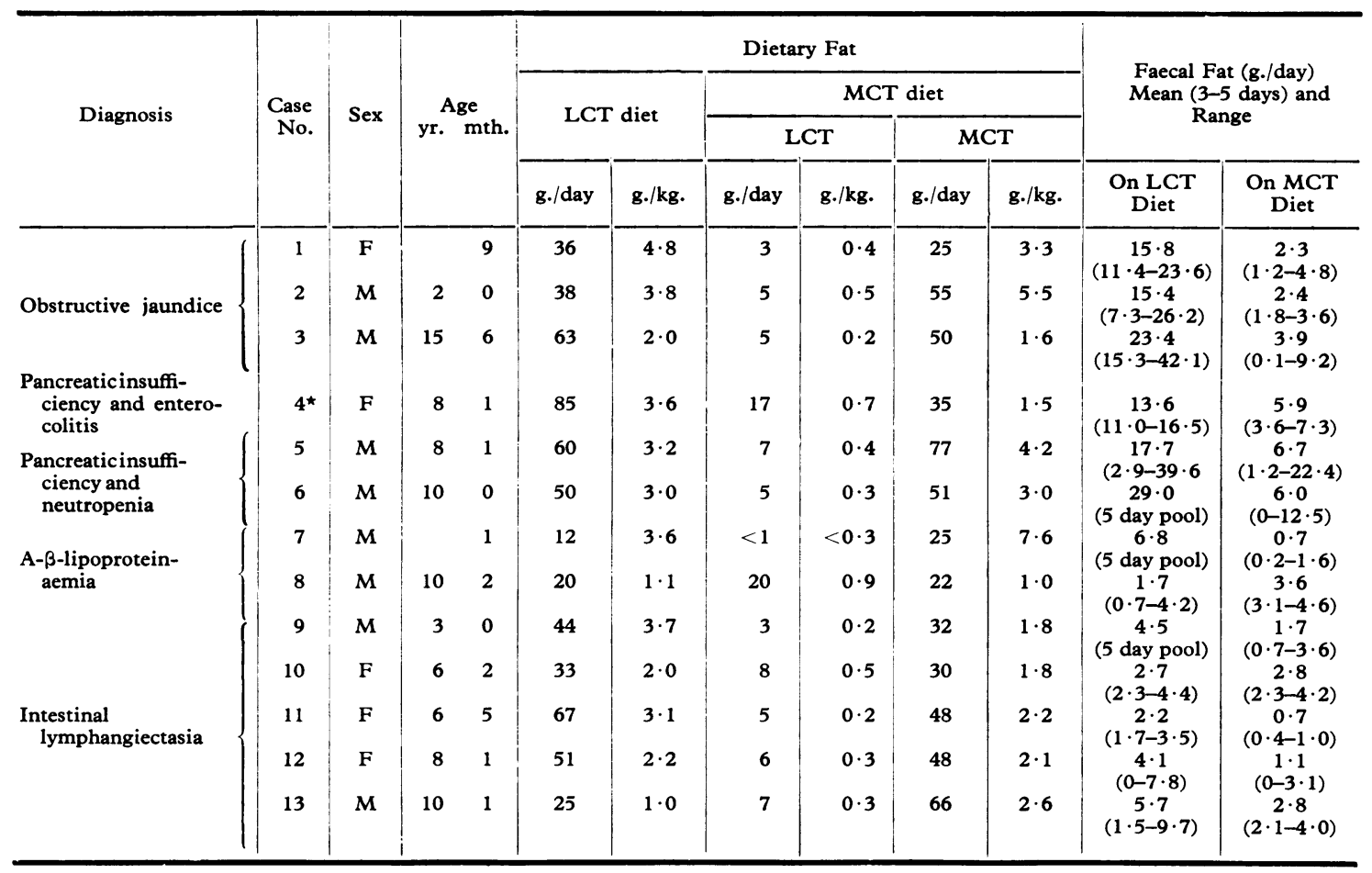

* Receiving pancreatic enzymes.

(Appendix II). With this method we obtained a mean recovery of added MCT of $91 \%$. The method was used for all estimations made while the children were receiving MCT and for the majority of the estimations made during LCT feeding. The rest of the faecal analyses on LCT diets were made by the van de Kamer method. Comparison between our method and the van de Kamer method for faeces containing only LCT showed that the results were the same. Faecal fat estimations were made on 24-hour collections and the results are expressed as means of 3-5 day consecutive collections.

TABLE II

Fatty Acid Composition of Triglyceride in MCT Foods

\begin{tabular}{|c|c|c|c|c|c|}
\hline & & \multicolumn{4}{|c|}{$\begin{array}{l}\text { Fatty Acid (g./100 g. total } \\
\text { fatty acids) }\end{array}$} \\
\hline & & C8:0 & $10: 0$ & $12: 0$ & $18: 2$ \\
\hline $\begin{array}{l}\text { Mead Johnson MCT oil } \\
\text { Mead Johnson formula } \\
\text { Unilever MCT oil }\end{array}$ & $\begin{array}{l}\cdots \\
\cdots \\
\cdots\end{array}$ & $\begin{array}{l}82 \\
82 \\
56\end{array}$ & $\begin{array}{l}16 \cdot 5 \\
12 \\
43\end{array}$ & $\begin{array}{l}1 \cdot 5 \\
1\end{array}$ & $\begin{array}{r}<1 \\
6 \\
<1\end{array}$ \\
\hline
\end{tabular}

$\star$ Portagen.
Serum albumin and immunoglobulins were estimated immunochemically by a single diffusion technique (Soothill and Rowe, 1967); gastro-intestinal protein loss was estimated using radioactive chromium chloride (Rubini and Sheehy, 1961), and haematological studies and liver function tests were performed by standard techniques.

\section{Results}

Results will be described in groups defined by the underlying cause of the malabsorption. Dietary fat intake and faecal fat output are given in Table I.

(1) Obstructive jaundice. In all 3 children on an ordinary intake of fat (LCT) steatorrhoea was gross. Considerable reduction in LCT abolished the steatorrhoea. The addition of MCT in amounts of 25-55 g./day to the small quantities of LCT did not cause a return of steatorrhoea. Analysis of the fatty acid pattern of the faecal lipids (Table III) showed that up to $4 \%$ of the ingested octanoic acid (C8:0) and 7-23\% of decanoic acid (C10:0) was not absorbed. In one child (Case 2) with severe pruritus the use of cholestyramine 




resulted in an increased faecal loss of C8:0 and C10:0 fatty acids (Table IV).

MCT diets have been continued for periods of 1 to 2 years without increase in growth velocity or improvement in results of liver function tests.

\section{TABLE IV}

Effect of Cholestyramine on Faecal Fats and Fatty Acids in Patient with Obstructive Jaundice on MCT Diet

\begin{tabular}{|c|c|c|c|}
\hline & & $\begin{array}{c}\text { Before } \\
\text { Cholestyramine }\end{array}$ & $\begin{array}{l}\text { With Cholestyra- } \\
\text { mine (8g./day) }\end{array}$ \\
\hline $\begin{array}{l}\text { Dietary fat } \\
\text { LCT (g./day) .. } \\
\text { MCT (g./day) .. } \\
\text { Faecal fat (g./day) } \\
\text { Mean (4-5 days) } \\
\text { Range . } \quad . .\end{array}$ & $\begin{array}{l}\cdots \\
\cdots\end{array}$ & $\begin{array}{c}4 \\
55 \\
2 \cdot 4 \\
(1 \cdot 8-3 \cdot 6)\end{array}$ & $\begin{array}{c}4 \\
56 \\
4 \cdot 7 \\
(1 \cdot 8-7 \cdot 7)\end{array}$ \\
\hline $\begin{array}{l}\% \text { composition } \\
\text { fatty acids } \\
\text { (g./100 g. total fatty } \\
\text { acid) }\end{array}$ & $\begin{array}{l}C 8: 0 \\
10: 0 \\
12: 0 \\
14: 0 \\
16: 0 \\
16: 1 \\
18: 0 \\
18: 1 \\
18: 2\end{array}$ & $\begin{array}{c}2 \cdot 4^{\star} \\
20 \cdot 5 \\
5 \cdot 7 \\
4 \cdot 7 \\
15 \cdot 1 \\
0 \cdot 9 \\
10 \cdot 4 \\
33 \cdot 4 \\
6 \cdot 3\end{array}$ & $\begin{array}{r}10 \cdot 7 \dagger \\
29 \cdot 8 \\
3 \cdot 3 \\
2 \cdot 4 \\
12 \cdot 0 \\
1 \cdot 1 \\
7 \cdot 5 \\
27 \cdot 1 \\
6 \cdot 2\end{array}$ \\
\hline $\begin{array}{l}\text { Faecal medium- } \\
\text { chain fatty acids as } \\
\% \text { of intake }\end{array}$ & $\begin{array}{l}C 8: 0 \\
10: 0\end{array}$ & $\begin{array}{r}<1 \\
5\end{array}$ & $\begin{array}{r}1 \\
12\end{array}$ \\
\hline
\end{tabular}

$\star$ Means of 2 days

+ Means of 4 days
One patient (Case 1) died of liver failure at the age of 22 months.

(2) Pancreatic insufficiency. MCT diets reduced faecal fat but normal values were not achieved. Pancreatic enzymes (Pancrex V forte tablets) given during the MCT dietary periods did not improve over-all fat absorption, though in 2 patients absorption of the medium-chain fatty acids was improved (Table V).

In only one patient (Case 6) have we been able to assess the effect of the diet on growth; his growth velocity has not changed over a 3-year period and his height and weight remain well below the 3 rd centile. Case 5 died from haemorrhage due to severe thrombocytopenia 7 months after the diet was started. Case 4 was given steroids for her enterocolitis 7 months after starting the diet.

(3) A- $\beta$-lipoproteinaemia. Case 7 was started on an MCT diet at the age of 2 months, and faecal fat became normal. Case 8 had been taking about $20 \mathrm{~g}$. LCT daily for 3 years, and on this regimen faecal fat was normal; he tolerated an additional 22 g. MCT without developing steatorrhoea.

Case 8 has not shown any change in growth velocity during 2 years on an MCT diet. Though Case 7 made good growth progress for a few weeks after the introduction of MCT, his subsequent progress was complicated by severe renal disease 
III

Patients on MCT Diets

(g./100 g. total fatty acids) (mean and range)

Faecal Medium-chain Fatty Acids as \% Intake

\begin{tabular}{|c|c|c|c|c|c|c|}
\hline $16: 0$ & $16: 1$ & $18: 0$ & $18: 1$ & $18: 2$ & $8: 0$ & $10: 0$ \\
\hline $\begin{array}{c}15 \cdot 9 \\
(14 \cdot 6-17 \cdot 5) \\
15 \cdot 1 \\
(14 \cdot 6,15 \cdot 6) \\
25 \cdot 8 \\
(26 \cdot 6,25 \cdot 0) \\
19 \cdot 1 \\
(8 \cdot 7-25 \cdot 8) \\
26 \cdot 2 \\
(25 \cdot 4,27 \cdot 0) \\
22 \cdot 9 \\
(20 \cdot 1-27 \cdot 2) \\
33 \cdot 4 \\
(32 \cdot 0-35 \cdot 4) \\
47 \cdot 8 \\
(45 \cdot 4-52 \cdot 5) \\
42 \cdot 6 \\
35 \cdot 6 \\
(31 \cdot 2,41 \cdot 0) \\
45 \cdot 6 \\
(42 \cdot 9,47 \cdot 7)\end{array}$ & $\begin{array}{c}1 \cdot 6 \\
(1 \cdot 0-1 \cdot 8) \\
0 \cdot 9 \\
(0 \cdot 7,1 \cdot 1) \\
<1 \\
<1 \\
(<2 \cdot 1) \\
<1 \\
2 \cdot 8 \\
(2 \cdot 4-3 \cdot 2) \\
<1 \\
(<1) \\
<1 \\
\\
<1 \\
1 \cdot 5 \\
(1 \cdot 4,1 \cdot 6) \\
<1\end{array}$ & $\begin{array}{c}5 \cdot 5 \\
(4 \cdot 6-6 \cdot 7) \\
10 \cdot 7 \\
(10 \cdot 3,11 \cdot 0) \\
22 \cdot 7 \\
(24 \cdot 2,21 \cdot 2) \\
10 \cdot 6 \\
(3 \cdot 9-17 \cdot 1) \\
44 \cdot 1 \\
(40 \cdot 8,47 \cdot 4) \\
8 \cdot 4 \\
(6 \cdot 8-10 \cdot 2) \\
36 \cdot 2 \\
(29 \cdot 7-46 \cdot 6) \\
22 \cdot 8 \\
(17 \cdot 9-29 \cdot 5) \\
39 \cdot 7 \\
23 \cdot 3 \\
(18 \cdot 7,28 \cdot 0) \\
26 \cdot 1 \\
(19 \cdot 9,30 \cdot 8)\end{array}$ & $\begin{array}{c}20 \cdot 1 \\
(15 \cdot 1-26 \cdot 1) \\
33 \cdot 4 \\
(29 \cdot 8,37 \cdot 0) \\
26 \cdot 3 \\
(22 \cdot 0,30 \cdot 5) \\
24 \cdot 1 \\
(10 \cdot 4-32 \cdot 9) \\
11 \cdot 7 \\
(11 \cdot 0,12 \cdot 4) \\
25 \cdot 8 \\
(20 \cdot 1-32 \cdot 5) \\
24 \cdot 1 \\
(13 \cdot 3-29 \cdot 8) \\
15 \cdot 3 \\
(12 \cdot 8-16 \cdot 8) \\
13 \cdot 3 \\
15 \cdot 8 \\
(13 \cdot 7,17 \cdot 8) \\
19 \cdot 4 \\
(14 \cdot 4,24 \cdot 8)\end{array}$ & $\begin{array}{c}26 \cdot 0 \\
(21 \cdot 6-27 \cdot 0) \\
6 \cdot 3 \\
(5 \cdot 7,6 \cdot 9) \\
6 \cdot 7 \\
(7 \cdot 3,6 \cdot 1) \\
4 \cdot 8 \\
(3 \cdot 8-5 \cdot 7) \\
0 \cdot 8 \\
(0 \cdot 7,0 \cdot 9) \\
17 \cdot 6 \\
(14 \cdot 3-20 \cdot 9) \\
3 \cdot 4 \\
(1 \cdot 8-5 \cdot 2) \\
7 \cdot 7 \\
(4 \cdot 0-9 \cdot 7) \\
2 \cdot 6 \\
18 \cdot 8 \\
(10 \cdot 2,27 \cdot 5) \\
3 \cdot 3 \\
(3 \cdot 1,3 \cdot 5)\end{array}$ & $\begin{array}{r}<1 \\
<1 \\
4 \\
6 \\
1 \\
<1 \\
<1 \\
<1 \\
<1 \\
<1 \\
<1\end{array}$ & $\begin{array}{r}9 \\
7 \\
23 \\
11 \\
15 \\
2 \\
<1 \\
<1 \\
<1 \\
<1 \\
<1\end{array}$ \\
\hline
\end{tabular}

and his height and weight at the age of 14 months were below the 3 rd centile.

(4) Intestinal lymphangiectasia. Steatorrhoea was not a prominent feature, though in 4 of the 5 children faecal fat decreased on MCT diets; in one child (Case 10) faecal fat was unchanged $(2 \cdot 8 \mathrm{~g}$./day). Analysis of faecal fatty acids indicated virtually complete absorption of MCT (Table III).

In all children gastro-intestinal protein loss was abnormal before dietary treatment started (4.4 $15.4 \%$ of the dose of radioactive $\mathrm{CrCl}_{3}$ ). In only one child (Case 9) has this investigation been repeated; after 1 year on an MCT diet, the loss $(7 \cdot 2 \%)$, though less than previously $(15 \cdot 4 \%)$,
TABLE VI

Serum Albumin in Intestinal Lymphangiectasia

\begin{tabular}{|c|c|c|c|}
\hline \multirow{2}{*}{ Case No } & \multicolumn{2}{|c|}{ Albumin (g./100 ml. serum) } & \multirow{2}{*}{$\begin{array}{l}\text { Duration of } \\
\text { MCT Diet } \\
\text { (mth.) }\end{array}$} \\
\hline & Before MCT & On MCT & \\
\hline $\begin{array}{r}9 \\
10 \\
11 \\
12 \\
13\end{array}$ & $\begin{array}{c}\text { Reduced }{ }^{\star} \\
2 \cdot 7 \\
2 \cdot 7 \\
3 \cdot 4 \\
1 \cdot 9\end{array}$ & $\begin{array}{c}3 \cdot 0 \\
4 \cdot 9 \\
\text { Reduced }^{\star} \\
5 \cdot 0 \\
3 \cdot 1\end{array}$ & $\begin{array}{r}29 \\
6 \\
9 \\
5 \\
11\end{array}$ \\
\hline
\end{tabular}

$\star$ By paper electrophoresis.

remained abnormal. Serum albumin levels before and after dietary treatment are given in Table VI; levels of $3.0 \mathrm{~g} . / 100 \mathrm{ml}$. or greater were achieved

\section{TABLE V}

Effect of Oral Pancreatic Enzymes on Faecal Fats and Fatty Acids in Patients with Pancreatic Insufficiency

\begin{tabular}{|c|c|c|c|c|c|c|c|c|c|c|c|c|c|c|c|}
\hline \multirow{3}{*}{$\begin{array}{c}\text { Case } \\
\text { No. }\end{array}$} & \multirow{3}{*}{$\begin{array}{c}\text { Oral } \\
\text { Enzymes }\end{array}$} & \multirow{2}{*}{\multicolumn{2}{|c|}{$\begin{array}{l}\text { Dietary Fat } \\
\text { (g./day) }\end{array}$}} & \multicolumn{10}{|c|}{ Faecal Fat } & \multirow{2}{*}{\multicolumn{2}{|c|}{$\begin{array}{l}\text { Medium- } \\
\text { chain Faecal } \\
\text { Fatty Acids } \\
\text { as \% Intake }\end{array}$}} \\
\hline & & & & \multirow{2}{*}{$\begin{array}{l}\text { g./day mean } \\
\text { (3-5 days) and } \\
\text { range }\end{array}$} & \multicolumn{9}{|c|}{$\begin{array}{l}\% \text { Composition Fatty Acids, Mean of } 2 \text { Observations } \\
\text { (g. } / 100 \text { g. total fatty acids) }\end{array}$} & & \\
\hline & & LCT & MCT & & C8:0 & $10: 0$ & $12: 0$ & $14: 0$ & $16: 0$ & $16: 1$ & $18: 0$ & $18: 1$ & $18: 2$ & C8:0 & $10: 0$ \\
\hline 4 & $\begin{array}{l}\text { Without } \\
\text { With }\end{array}$ & $\begin{array}{l}18 \\
16\end{array}$ & $\begin{array}{l}36 \\
35\end{array}$ & $\begin{array}{l}2 \cdot 9(1 \cdot 6-6 \cdot 6) \\
5 \cdot 9(3 \cdot 6-7 \cdot 3)\end{array}$ & & & & & & & & & & & \\
\hline 5 & Without & 7 & 77 & $6 \cdot 7(1 \cdot 2-22 \cdot 4)$ & $20 \cdot 8$ & $36 \cdot 1$ & $1 \cdot 0$ & $<1$ & $14 \cdot 1$ & $<1$ & $6 \cdot 4$ & $13 \cdot 8$ & $6 \cdot 5$ & 10 & 14 \\
\hline & $\begin{array}{c}\text { With } \\
\text { Without }\end{array}$ & $\begin{array}{l}7 \\
5\end{array}$ & 60 & $4 \cdot 1(2 \cdot 1-6 \cdot 6)$ & $2 \cdot 5$ & $23 \cdot 4$ & $<1$ & 1.7 & $27 \cdot 0$ & 1.4 & $17 \cdot 6$ & $18 \cdot 5$ & $7 \cdot 6$ & $<1$ & 8 \\
\hline 0 & $\begin{array}{l}\text { Without } \\
\text { With }\end{array}$ & $\begin{array}{l}5 \\
6\end{array}$ & 51 & $\begin{array}{l}6 \cdot 0(0-12 \cdot 5) \\
8 \cdot 0(0-24 \cdot 0)\end{array}$ & $\begin{array}{r}3.5 \\
\star<1\end{array}$ & 8.5 & 1.5 & 3.5 & $26 \cdot 2$ & $<1$ & $44 \cdot 1$ & $11 \cdot 7$ & $<1$ & $<1$ & 12 \\
\hline & & & & & & & & & & & & & & & \\
\hline
\end{tabular}

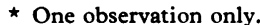


in 4 of the 5 children. In all the children clinical evidence of oedema either disappeared or lessened, and in 2 of the 3 children who had previously required diuretics these drugs could be discontinued after 7-24 months on MCT diets. No consistent changes were observed in serum immunoglobulin levels after the introduction of MCT. Lymphopenia (total lymphocyte count below 1500 /cu.mm.) was observed before treatment in all children; counts after MCT showed considerable variability, and no significant rise occurred.

Data on growth are available over too short a period ( $<1$ year) in most children to enable the effect of the MCT diets on height velocity to be conclusively interpreted. In one child (Case 9) there was an increase in height from below the 3rd centile before the introduction of the MCT diet to the 25 th centile 2 years after starting the diet.

\section{Discussion}

The need for modifications of the standard methods of faecal fat analysis for subjects receiving MCT has been emphasized by Saunders (1967), and though the 'losses' of medium-chain fatty acids during the extraction stage of the van der Kamer method may be counter-balanced by 'gains' in the titrimetric determination (Senior, 1968), such a method cannot be regarded as satisfactory for faeces containing MCT. Furthermore, analysis of the individual fatty acids in faeces cannot be obtained unless extraction of all the fatty acids is complete. Our method has proved satisfactory for faeces containing MCT, and is similar to a method described by Friedner and Moberg (1967).

Our study of children with malabsorption demonstrates the more efficient absorption of MCT compared with LCT in all the situations investigated. It also shows that the efficiency of MCT absorption varies according to the underlying physiological disturbance. Though MCT is miscible with water, bile salts undoubtedly play a part in its absorption (Valdivieso and Schwabe, 1965a; Greenberger, Rodgers, and Isselbacher, 1966). In some adult patients with cirrhosis, steatorrhoea has persisted on MCT diets (Linscheer et al., 1966). In our patients with obstructive jaundice almost complete absorption of octanoic acid occurred, no more than $4 \%$ of the intake appearing in the faeces, but decanoic acid was less well absorbed, $7-23 \%$ of the intake appearing in the faeces. The role of bile was further demonstrated by the findings in the patient given cholestyramine, which reduced the quantity of available bile acids and increased the faecal loss of both octanoic and decanoic acids. Because of the difference in the efficiency of absorption between octanoic and decanoic acids, the over-all absorption of an MCT preparation depends upon its composition, and preparations containing high proportions of octanoic acid are likely to be well absorbed even when bile salts are grossly deficient.

The importance of intraluminar hydrolysis of MCT by pancreatic lipase has been investigated by several workers. Hydrolysis of MCT is virtually complete in the presence of adequate pancreatic lipase (Hashim et al., 1964) and impaired in its absence (Valdivieso and Schwabe, 1965b). MCT can, however, be absorbed unhydrolysed (Playoust and Isselbacher, 1964), and its absorption in patients with pancreatic disease, both in adults (Smits, Wilding, and Cooke, 1968) and in children with cystic fibrosis (Kuo and Huang, 1965; Anderson, 1968), has been demonstrated. Absorption, however, does not appear to be complete, and in our patients with pancreatic insufficiency we have found less efficient absorption of octanoic and decanoic acids than in any of the other patients. The efficacy of administered pancreatic enzymes in promoting fat absorption in patients with pancreatic disease is controversial (Dyer and Dawson, 1968; Norman and Gibbons, 1968). We have been unable to demonstrate any increase in total fat absorption when these enzymes were given to our patients with pancreatic insufficiency, though there was some improvement in the absorption of medium-chain fatty acids. We have not investigated the effect of enzyme therapy on protein absorption, and do not wish to suggest that MCT replaces enzymes in the management of pancreatic disorders.

The complete absorption of MCT in conditions in which the intraluminar phase of fat digestion is unimpaired and mucosal cell function is normal is demonstrated in our patients with intestinal lymphangiectasia, in none of whom was more than a trace $(<1 \%)$ of medium-chain fatty acids detected in the faeces. Complete absorption of MCT was also observed in one patient with a- $\beta$-lipoproteinaemia, though in the other, small quantities of faecal octanoic and decanoic acids were found. In this patient (Case 7) relatively large amounts of MCT were being given, and entry into, or lipolysis within, the mucosal cells may have been limited by the accumulation of LCT in these cells. Even on diets virtually free from LCT such mucosal accumulation is not completely abolished (Ways et al., 1967).

The control of steatorrhoea achieved in all our patients by the use of MCT diets has been of considerable clinical benefit in improving their 
general well-being, and in reducing the number and offensiveness of the stools. This effect, which is due to the reduction in the LCT content of the diets, can of course be achieved by low LCT diets alone. Such diets, however, are unpalatable, and may be difficult to maintain over long periods. The use of MCT greatly adds to palatability, as the oil can be used for frying and baking, and recipes have been described by Francis and Dixon (1969) and Schizas et al. (1967). Certain precautions need to be emphasized: because of its high osmolarity gastro-intestinal side-effects (abdominal pain, vomiting, and diarrhoea) occur if the oil is drunk undiluted. In drinks, the oil should be diluted with at least equal volumes of other fluid and taken slowly. The introduction of MCT into the diet should be made gradually over a period of about one week or even longer in the case of young infants. When MCT oil is used for frying the temperature should be kept as low as possible because the oil smokes easily and acquires a bitter taste if overheated. For the latter reason it is also inadvisable to re-use the oil.

The nutritional value of MCT diets in promoting increased growth rates has been difficult to assess in our patients, because the underlying disease processes may have contributed in varying degrees to growth retardation. In the children with obstructive jaundice, we did not observe the improvement in growth reported by Burke and Danks (1966) in their patients with liver disease. The two series, however, are not strictly comparable, as we did not study babies in the neonatal period, and steroid therapy contributed to growth retardation in 2 of our patients. Burke and Danks also reported improvement in liver function in a 13-year-old girl; we did not observe such improvement in a 15-year-old boy (Case 3). Further long-term studies are needed to evaluate the effect of MCT diets on the course of liver disease. From our studies of serum lipids in these patients (Tamir et al., 1969) we have no evidence that the hepatic metabolism of absorbed medium-chain fatty acids is abnormal in patients with liver disease. The nutritional value of MCT in children with pancreatic disease has been most extensively documented in patients with cystic fibrosis (Kuo and Huang, 1965; Anderson, 1968); we have no experience in the use of MCT in this condition. In our surviving patient with pancreatic insufficiency and neutropenia (Case 6), an MCT diet has not improved his growth rate though steatorrhoea has been controlled; we are unable to say to what degree his growth failure may be due to the underlying disease process or to his poor appetite. In one patient with a- $\beta$-lipoproteinaemia (Case 8 ), whose height and weight were well below the 3rd centile, the growth rate did not alter when steatorrhoea was contolled by a low LCT diet alone or when MCT was added. Possibly his small stature is due to causes other than malabsorption, as in 2 other children with this condition growth improved markedly after control of steatorrhoea by a low LCT diet (Lloyd, 1968; A. G. Hesling, J. K. Lloyd, A. S. Fosbrooke, M. M. Segall, and O. H. Wolff, unpublished data). In our second patient with a- $\beta$-lipoproteinaemia given MCT (Case 7) growth may have been affected by his renal disease.

The most satisfactory clinical effects of MCT diets have been observed in the children with intestinal lymphangiectasia. The mechanisms for the increased protein loss into the bowel in this condition are not fully understood; protein may be taken up by foamy macrophages in the intestinal wall (Dooren, van Gelderen, and Vink, 1961), or rupture of the dilated intestinal lymphatics may occur. In favour of the latter hypothesis is the finding of chylous fluid in the intestinal lumen (Stoelinga, van Muster, and Slooff, 1963). Reduction in the flow of intestinal lymph by restriction of dietary LCT has been shown to decrease the turnover of injected ${ }^{131} \mathrm{I}$-albumin (Jeffries, Chapman, and Sleisenger, 1964), and a similar effect has been observed on an MCT diet (Holt, 1964).

In most of our patients, evidence of intestinal protein loss persisted on MCT diets, as shown by low lymphocyte counts (indicating interruption of the recirculation of lymphocytes as described by Poley et al., 1967), and in one patient by abnormal faecal loss of radioactive $\mathrm{CrCl}_{3}$. Nevertheless, a decrease in the over-all rate of protein turnover may be deduced from the improvement in serum albumin levels, disappearance of generalized oedema, and the ability to discontinue diuretic therapy in 2 children. A marked increase in growth rate occurred in the one patient treated for a long enough period to assess growth velocity accurately.

\section{Summary}

Medium-chain triglyceride (MCT) diets have been used in the treatment of 13 children with malabsorption due to four groups of disorders: obstructive jaundice, pancreatic insufficiency, $a-\beta-$ lipoproteinaemia, and intestinal lymphangiectasia. The diets consisted of a low intake of ordinary dietary fat (long-chain triglyceride) together with the addition of medium-chain triglyceride as an oil for cooking or in a milk formula. The role of MCT in the diet is to increase palatability and 
provide additional calories. A method for faecal fat estimation suitable for use in patients receiving MCT diets is described.

MCT diets controlled the steatorrhoea in all four groups of disorders. Analysis of the faecal fatty acid pattern showed that MCT absorption was somewhat impaired where bile or pancreatic lipase was deficient, but was virtually complete in intestinal lymphangiectasia and a- $\beta$-lipoproteinaemia where the intraluminar phase of fat digestion was normal.

Control of steatorrhoea improved the general well-being of all the children. In those with lymphangiectasia serum albumin levels rose, generalized oedema disappeared, and in one child marked acceleration of growth occurred. No significant effect on growth rate was observed in the children with obstructive jaundice, pancreatic insufficiency, or a- $\beta$-lipoproteinaemia, though in these children factors other than malabsorption may have contributed to their growth retardation.

We thank our colleagues who have referred patients to us, Miss D. M. Francis and Mrs. C. Carter for dietetic help, Dr. D. Croft of St. Thomas' Hospital for performing the radioactive $\mathrm{CrCl}_{3}$ studies, the Mead Johnson Company and Unilever Ltd. for supplies of MCT, and the Medical Research Council for financial assistance. One of us (M. M. S.) was in receipt of a Wellcome Trust fellowship.

\section{REFERENCES}

Anderson, C. M. (1968). The value of medium chain triglycerides in malabsorptive disorders in childhood. In Medium Chain Triglycerides, p. 219 . Ed. by J. R. Senior. University of Pennsylvania Press, Philadelphia.

Burke, V., and Anderson, C. M. (1967). Experience with medium chain triglycerides in malabsorptive states in childhood. Aust. Paediat. F., 3, 135.

- and Danks, D. M. (1966). Medium-chain triglyceride diet: its use in treatment of liver disease. Brit. med. $\mathcal{F} ., 2,1050$.

Cancio, M., and Menéndez-Corrada, R. (1964). Absorption of medium chain triglycerides in tropical sprue. Proc. Soc. exp. Biol. (N.Y.), 117, 182.

Cooke, W. T., and Brooke, B. N. (1955). Non-specific enterocolitis. Quart. F. Med., 24, 1.

Cottom, D. G., London, D. R., and Wilson, B. D. R. (1961). Neonatal oedema due to exudative enteropathy. Lancet, 2, 1009.

Dooren, L. J., van Gelderen, H. H., and Vink, C. L. J. (1961). Exudative enteropathy. Acta paediat. (Uppsala), 50, 249.

Dyer, N. H., and Dawson, A. M. (1968). Malabsorption. Brit. med. $\mathcal{F}$., 2, 225.

Forsyth, C. C., Lloyd, J. K., and Fosbrooke, A. S. (1965). A- $\beta-$ lipoproteinaemia. Arch. Dis. Childh., 40, 47.

Fosbrooke, A. S., and Tamir, I. (1968). A modified method for the preparation of methyl esters of a mixture of medium-chain and long-chain fatty acids. Clin. chim. Acta, 20, 517.

Francis, D. M., and Dixon, D. (1969). Diets for Sick Children. Blackwell, Oxford. In the press.

Friedner, S., and Moberg, S. (1967). Determination of total faecal lipids including medium-chain triglycerides. Clin. chim. Acta, 18, 345.

Greenberger, N. J., Rodgers, J. B., and Isselbacher, K. J. (1966). Absorption of medium and long chain triglycerides: factors influencing their hydrolysis and transport. $\mathcal{f}$. clin. Invest., 45, 217.
Hashim, S. A., Bergen, S. S., Jr., Krell, K., and Van Itallie, T. B. (1964). Intestinal absorption and mode of transport in portal vein of medium chain fatty acids. ibid., 43, 1238.

Holt, P. R. (1964). Dietary treatment of protein loss in intestinal lymphangiectasia. Pediatrics, 34, 629.

, Hashim, S. A., and Van Itallie, T. B. (1965). Treatment of malabsorption syndrome and exudative enteropathy with synthetic medium chain triglycerides. Amer. F. Gastroent., 43, 549.

Isselbacher, K. J., Scheig, R., Plotkin, G. R., and Caulfield, J. B. (1964). Congenital $\beta$-lipoprotein deficiency: an hereditary disorder involving a defect in the absorption and transport of lipids. Medicine (Baltimore), 43, 347.

Jeffries, G. H., Chapman, A., and Sleisenger, M. H. (1964). Lowfat diet in intestinal lymphangiectasia: its effect on albumin metabolism. New Engl. F. Med., 270, 761.

van de Kamer, J. H., ten Bokkel Huinink, H., and Weyers, H. A. (1949). Rapid method for the determination of fat in feces. f. biol. Chem., $177,347$.

Kaunitz, H., Slanetz, C. A., Johnson, R. E., Babayan, V. K., and Barsky, G. (1958). Nutritional properties of the triglycerides of saturated fatty acids of medium-chain length. $\mathcal{F}$. Amer. Oil. Chem. Soc., 35, 10.

Kuo, P. T., and Huang, N. N. (1965). The effect of medium chain triglyceride upon fat absorption and plasma lipid and depot fat of children with cystic fibrosis of the pancreas. f. clin. Invest., 44, 1924.

Linscheer, W. G., Patterson, J. F., Moore, E. W., Clermont, R. J., Robins, S. J., and Chalmers, T. C. (1966). Medium and long chain fat absorption in patients with cirrhosis. ibid., 45, 1317.

Lloyd, J. K. (1968). Disorders of the serum lipoproteins. I. Lipoprotein deficiency states. Arch. Dis. Childh., 43, 393.

Norman, A. P., and Gibbons, I. S. E. (1968). Pancreatic extracts in cystic fibrosis. Brit. med. $\mathcal{F} ., 2,621$.

Playoust, M. R., and Isselbacher, K. J. (1961). Studies on the intestinal absorption and intramucosal lipolysis of a medium chain triglyceride. F. clin. Invest., 43, 878.

Poley, J. R., Lesch, P., Hitzig, W. H., and Prader, A. (1967). Chylöser Ascites: Untersuchungen über den Eiweissstoffwechsel und über den Einfluss des Nahrungsfetts auf die Ascitesproduktion. Helv. paediat. Acta, 22, 81.

Rubini, M. E., and Sheehy, T. W. (1961). Exudative enteropathy. I. A comparative study of $\mathrm{Cr}^{51} \mathrm{Cl}_{3}$ and $\mathrm{I}^{131} \mathrm{PVP}$. F. Lab. clin. Med., 58, 892.

Saunders, D. R. (1967). Medium chain triglycerides and the van de Kamer method. Gastroenterology, 52, 135.

Schizas, A. A., Cremen, J. A., Larson, E., and O'Brien, R. (1967). Medium chain triglycerides: use in food preparation. $\mathcal{f}$. Amer. diet. Ass., 51, 228.

Senior, J. R. (1968). Introduction to triglyceride absorption. In Medium Chain Triglycerides, p. 3. Ed. by J. R. Senior. University of Pennsylvania Press, Philadelphia.

Smits, B. J., Wilding, P., and Cooke, W. T. (1968). Ready absorption of medium chain triglyceride in the steatorrhoea syndrome. Gut, 9, 28.

Soothill, J. F., and Rowe, D. S. (1967). Estimation of plasma proteins by gel diffusion precipitin techniques. In Symposium Series on Immunobiology Standards, 4, 37. Karger, Basle.

Stoelinga, G. B. A., van Muster, P. J. J., and Slooff, J. P. (1963). Chylous effusions into the intestine in a patient with proteinlosing gastroenteropathy. Pediatrics, 31, 1011.

Tamir, I., Gould, S., Fosbrooke, A. S., and Lloyd, J. K. (1969). Serum and adipose tissue lipids in children receiving mediumchain triglyceride diets. Arch. Dis. Childh., 44, 180.

Valdivieso, V. D., and Schwabe, A. D. (1965a). Factors influencing the absorption of a medium chain triglyceride. I. The role of bile in the intraluminar phase of absorption. Gastroenterology, 48, 331.

- and - (1965b). Factors influencing the absorption of a medium chain triglyceride. II. The role of pancreatic juice in the intraluminar phase of absorption. ibid., 48, 336.

Ways, P. O., Parmentier, C. M., Kayden, H. J., Jones, J. W., Saunders, D. R., and Rubin, C. E. (1967). Studies on the absorptive defect for triglyceride in abetalipoproteinemia. f. clin. Invest., 46, 35.

Winawer, S. J., Broitman, S. A., Wolochow, D. A., Osborne, M. P., and Zamcheck, N. (1966). Successful management 
of massive small-bowel resection based on assessment of absorption defects and nutritional needs. New Engl. F. Med., 274, 72.

Yssing, M., Jensen, H., and Jarnum, S. (1967). Dietary treatment of protein-losing enteropathy. Acta. paediat. scand., 56, 173.

Zurier, R. B., Campbell, R. G., Hashim, S. A., and Van Itallie, T. B. (1966). Use of medium-chain triglyceride in management of patients with massive resection of the small intestine. New Engl. F. Med., 274, 490.

\section{APPENDIX I}

Case 1. (Obstructive jaundice). Female, third child of unrelated parents, had persistent jaundice and slow weight gain from age of 10 days.

Laparotomy at 8 months showed no extrahepatic biliary obstruction, and the liver was cirrhotic; histology and further investigations did not reveal the cause. Serum bilirubin was $18.5 \mathrm{mg} .100 \mathrm{ml}$. Gross steatorrhoea was present; her height was on 50th centile and weight on 3rd centile. An MCT diet was started at 10 months and steatorrhoea was controlled (Table I). At 12 months, steroids were given because of deteriorating liver function. Deterioration continued and she died in liver failure at 22 months. Necropsy showed intrahepatic biliary atresia.

Case 2. (Obstructive jaundice). Male, the elder child of unrelated parents, had persistent jaundice from the age of 6 weeks.

Steroids were given for 6 weeks from the age of 2 months. During the next year, growth was poor, jaundice fluctuated, and pruritus developed. At laparotomy (age 16 months) several calculi were removed from the gall-bladder; cholangiogram showed no extrahepatic biliary obstruction, and liver histology showed a few small bile-ducts, 'giant cell transformation', and early biliary cirrhosis. Further investigations failed to reveal the cause. Serum bilirubin was $11 \mathrm{mg}$./ $100 \mathrm{ml}$. Gross steatorrhoea was present, and his height and weight were on 3rd centile. Steroid therapy was restarted and cholestyramine was given for pruritus. There was no clinical improvement. An MCT diet was started at 2 years and steatorrhoea was controlled (Table I). There was general clinical improvement and pruritus became less severe when cholestyramine dosage was increased. Tests of liver function, however, showed no consistent change. Growth continued below 3rd centile and steroid therapy was stopped at age of 3 years.

Case 3. (Obstructive jaundice). Male, third child of related parents (second cousins), had persistent jaundice from the age of 17 days. Growth was markedly retarded, and he developed severe pruritus. Frequent attacks of unexplained vomiting and diarrhoea occurred from age of 18 months.

Laparotomy at 28 months showed no extrahepatic biliary obstruction; histology showed 'subacute hepatitis'. Jaundice persisted and percutaneous liver biopsy at 9 years showed mild cirrhosis.

Further investigations at 15 years failed to reveal the cause of liver disease. The gall-bladder contained a calculus which was removed. Cholangiogram showed normal ex trahepatic ducts; histology showed presence of intrahepatic bile-ducts. Serum bilirubin was $4 \mathrm{mg}$./ $100 \mathrm{ml}$. Gross steatorrhoea was present, and his height and weight were both well below 3rd centile. An MCT diet was started with improvement in the steatorrhoea (Table I) and in his general health. Subsequently tests of liver function have shown no consistent change, and his rate of growth has not acceleratel. No further attacks of vomiting and diarrhoea have occurred.

Case 4. (Pancreatic insufficiency and enterocolitis). Female, third child of unrelated parents, was well until 3 years of age when she developed persistent loose stools with blood and mucus.

At 4 years investigations showed steatorrhoea and low enzyme activity in duodenal juice. Barium enema and sigmoidoscopy were normal, and laparotomy revealed no abnormalities. Treatment with pancreatin and courses of prednisolone enemata and sulphasalazine were given. She continued to have diarrhoea with blood and mucus though her growth rate remained normal. Intramuscular iron was required for anaemia.

An MCT diet was started at age of 8 years. Steatorrhoea was controlled (Table I), and pancreatin could be stopped. However, diarrhoea with blood and mucus persisted, and further barium studies showed enterocolitis of the type described by Cooke and Brooke (1955). Treatment with systemic steroids was started and her diarrhoea and intestinal bleeding have stopped.

Case 5. (Pancreatic insufficiency and neutropenia). Male, elder child of unrelated parents, had diarrhoea from the age of 9 weeks. Diagnosis was thought to be cystic fibrosis and he was started on pancreatin. However, he failed to thrive and had continued diarrhoea and respiratory infections. At the age of 2 years his height and weight were below 3rd centile. Sweat sodium was found to be normal but duodenal juice enzyme activity was low. Peripheral blood showed neutropenia and thrombocytopenia. Diagnosis of pancreatic hypoplasia was made by laparotomy and biopsy. Pancreatin was continued, but his growth remained poor. Steroids were given in an attempt to control the haematological abnormalities. He had recurrent skin sepsis.

At age of 8 years gross steatorrhoea was present and his height and weight were below 3 rd centile. An MCT diet was started and his steatorrhoea improved over-all but still fluctuated widely (Table I). Skin sepsis continued. At the age of 81 years neutropenia and thrombocytopenia became more severe and at the age of $8 \frac{1}{2}$ years he died of pulmonary haemorrhage.

Case 6. (Pancreatic insufficiency and neutropenia). Male, only child of unrelated parents, had 
diarrhoea from age of 2 weeks. Diagnosis was thought to be cystic fibrosis and he was started on pancreatin. At age of 3 years his height and weight were below 3rd centile. Sweat sodium was found to be normal but duodenal juice enzyme activity was low. During an attack of measles he was found to have neutropenia, lymphopenia, and thrombocytopenia. Glycosuria was present but the blood sugar was normal. There was also mild generalized aminoaciduria; plasma amino acids were normal. Pancreatin was continued; he had variable diarrhoea and a number of respiratory infections. Growth failure persisted.

$\mathrm{He}$ was investigated again at 10 years and showed height and weight still well below 3rd centile; bone age was 7 years. There was gross steatorrhoea. Duodenal enzyme activity was low after stimulation with pancreozymin and secretin. Jejunal biopsy was normal. An oral glucose tolerance test showed a mildly diabetic curve. Intermittent glycosuria persisted, but urinary amino acids became normal. Neutropenia persisted; the bone-marrow showed marked depletion of granulocyte precursors. An MCT diet was started and pancreatin continued. Steatorrhoea was reduced (Table I) but his growth rate has not increased. Chlorpropamide was started at the age of $12 \frac{1}{2}$ years because of deterioration in glucose tolerance, but growth rate has remained unchanged.

Case 7. (A- $\beta$-lipoproteinaemia). Male, fourth child of unrelated parents, birthweight $3.0 \mathrm{~kg}$. Loose offensive stools noted from age of 2 weeks, with abdominal distension and poor weight gain. One sib had been diagnosed as having coeliac disease and had died at 20 months from haemorrhage.

By 4 weeks haemoglobin had fallen to $7 \mathrm{~g} . / 100 \mathrm{ml}$., and acanthocytes were found in peripheral blood. Serum cholesterol was $38 \mathrm{mg} . / 100 \mathrm{ml}$., and absence of $\beta$-lipoprotein was confirmed by paper electrophoresis. Faecal fat was 6.8 g./day. Anaemia was corrected by blood transfusion. An MCT diet was started at 2 months and steatorrhoea was abolished (Table I). Initial progress was good but at 5 months of age acute pyelonephritis developed, and investigation showed gross bilateral hydronephrosis and hydroureter. At laparotomy bilateral ureterovesical obstruction was found and ureteric reimplantation was performed, but urinary infection continued, and he developed renal calculi which were removed at age of 1 year. Blood urea remained normal but height and weight have stayed below 3rd centile.

Case 8. (A- $\beta$-lipoproteinaemia). Male, only child of related parents (first cousins). Diagnosis was made at age of 7 years and the details have been reported (Forsyth, Lloyd, and Fosbrooke, 1965). A low fat diet ( $20 \mathrm{~g}$./day) was started at this time and steatorrhoea was controlled but growth has continued well below 3rd centile for both height and weight. An MCT diet was started at age of 10 years. Steatorrhoea has not recurred (Table I), but his growth rate has not improved.
Case 9. (Intestinal lymphangiectasia). Male, younger child of unrelated parents, recurrent oedema of limbs and face noted from age of 1 month, and diarrhoea and poor appetite from 8 months.

At 1 year, hypoproteinaemia was found (serum total protein $3.0 \mathrm{~g} .100 \mathrm{ml}$.). He was treated with a glutenfree, high-protein diet without improvement. $\gamma$ globulin injections were given because of upper respiratory infections and low IgG levels. At age of $2 \frac{1}{2}$ years height and weight were on 3rd centile. Increased gastro-intestinal protein loss was demonstrated, but there was no steatorrhoea. Diagnosis of intestinal lymphangiectasia was suggested by barium meal, and confirmed by laparotomy and intestinal biopsy. Peripheral oedema was controlled by diuretics and $\gamma$-globulin injections were stopped. Prednisolone was given for 6 months without improvement. An MCT diet was started at age of 3 years and faecal fat was reduced (Table $\mathrm{I}$ ). During the next 2 years marked clinical improvement occurred, diarrhoea ceased, and oedema disappeared; diuretics were stopped. Barium meal and jejunal biopsy showed improvement in the mucosal pattern. Gastro-intestinal protein loss was reduced but remained excessive. By age of 5 years both height and weight had increased to 25 th centile.

Case 10. (Intestinal lymphangiectasia). Female younger sib of sister who died aged 5 weeks with generalized oedema. The early history has been described by Cottom, London, and Wilson (1961). Oedema noted shortly after birth.

Protein-losing enteropathy was demonstrated, and low serum proteins (particularly $\gamma$-globulin) were found; $\gamma$-globulin injections were given. At $2 \frac{1}{2}$ years a gluten-free diet was introduced without improvement. Oedema was controlled by diuretics. Intestinal lymphangiectasia was diagnosed on a barium meal. There was no steatorrhoea. An MCT diet was started at age of 6 years and her clinical condition improved. Diuretics could be stopped after six months and $\gamma$ globulin after one year.

Case 11. (Intestinal lymphangiectasia). Female, second of 4 children of unrelated parents. Oedema of right foot and right side of face noted in neonatal period; later left hand also became swollen.

At age of 4 years she became dyspnoeic due to bilateral pleural effusions; the fluid was not chylous. She was considered to have pulmonary lymphangiectasia. She was treated with diuretics, steroids, antispasmodics, and antibiotics. Steroid therapy was stopped after one year but diuretics were continued, and repeated left pleural aspirations were necessary over the next $2 \frac{1}{2}$ years. At the age of 6 years increased gastro-intestinal protein loss was demonstrated; there was no steatorrhoea. An MCT diet was started and faecal fat decreased (Table I). Her clinical condition improved and no further pleural aspirations were necessary, though diuretics have had to be continued to control oedema. Her height has remained between $3 \mathrm{rd}$ and 10 th centile. 
Case 12. (Intestinal lymphangiectasia). Female, third child of unrelated parents. Oedema of left foot noted for first time at age of 6 years.

Oedema subsided spontaneously but at age of 7 years she had an acute episode of dependent oedema and ascites, at which time serum albumin was $2.7 \mathrm{~g} . /$ $100 \mathrm{ml}$. Oedema and ascites again resolved spontaneously, but she continued to have recurrent dependent oedema. At age of 8 years, her height was on 3rd centile and her weight (while oedematous) on 25th centile. Increased gastro-intestinal protein loss was demonstrated; there was no steatorrhoea. A barium meal was characteristic of lymphangiectasia. An MCT diet was started and faecal fat decreased (Table I). There has been no further oedema.

Case 13. (Intestinal lymphangiectasia). Male, second child of unrelated parents, oedema of right arm and right side of face noted at birth.

At age of 1 year he had pneumococcal meningitis and pneumonia, and developed generalized oedema. At 2 years he had an acute episode of diarrhoea and thereafter continued to have loose offensive stools. At 4 years, he was circumcised and histology of the prepuce showed dilated lymphatics. The following year he had a second attack of pneumonia. At 6 years steatorrhoea and increased gastro-intestinal protein loss were demonstrated and jejunal biopsy at laparotomy showed lymphangiectasia. He was treated with a gluten-free, milk-free diet, and given blood and plasma transfusions. Later a low-fat, low-sucrose diet was introduced, and he remained well, but dependent oedema occurred during intercurrent respiratory infections. An MCT diet was started at age of 10 years and steatorrhoea was controlled (Table I). He has had no further diarrhoea or dependent oedema, and his facial oedema has markedly decreased. His height has remained between the 3rd and 10th centile.

\section{APPENDIX II}

Method for determination of faecal fat suitable for analyses in patients taking MCT diets

Reagents and apparatus. Ethanol (or industrial spirit), $40 \% \mathrm{w} / \mathrm{v}$ potassium hydroxide (aqueous), $36 \% \mathrm{w} / \mathrm{v}$ hydrochloric acid (concentrated), redistilled petroleum ether, boiling range $40-60{ }^{\circ} \mathrm{C}$., non-volatile residue $<0.0004 \% \mathrm{w} / \mathrm{v}$, Silverson homogenizer with pump attachment, $100 \mathrm{ml}$. and $250 \mathrm{ml}$. glass-stoppered conical flasks, 3-4 mm. diameter glass beads, reflux condensers (Davies pattern with ground glass joints), electrically-heated sand-bath (Gallenkamp), suction bulb with 3-way valves ('Propipette', Hoslab), and $80 \mathrm{ml}$. tilt-measure (Quickfit and Quartz).

\section{Procedure}

(i) Homogenization. Faeces are mixed with about 5 volumes of water using a Silverson homogenizer with pump attachment. The weight (g.) of homogenate is recorded.

(ii) Saponification. A $20 \mathrm{~g}$. aliquot of homogenate is transferred to a tared $100 \mathrm{ml}$. conical flask; $6 \mathrm{ml}$. ethanol, $14 \mathrm{ml}$. potassium hydroxide, and several glass beads are added, and the flask is heated under reflux in the sand-bath for 20 minutes.

(iii) Acidification and triple extraction. The flask is mixed by swirling before taking a $14 \mathrm{ml}$. aliquot into a $250 \mathrm{ml}$. conical flask containing $7 \mathrm{ml}$. hydrochloric acid. The acidified mixture is extracted three times with $80 \mathrm{ml}$. petroleum ether, and each time the stoppered flask is shaken vigorously for 1 minute. The flask contents are poured into a $250 \mathrm{ml}$. separating funnel, the lower (aqueous layer) is returned to the $250 \mathrm{ml}$. flask for re-extraction, and the upper (petroleum) layer is collected in a $400 \mathrm{ml}$. beaker. The pooled petroleum ether extract (about $240 \mathrm{ml}$.) is evaporated to dryness under an air-stream in a fume cupboard. The residue is redissolved in petroleum ether, transferred quantitatively to a glass-stoppered test-tube, and the volume made up to $25 \mathrm{ml}$. The tube is centrifuged to sediment any insoluble material.

(iv) Gravimetric estimation. $20 \mathrm{ml}$. supernatant solution is transferred to a tared $100 \mathrm{ml}$. beaker and the petroleum ether evaporated using a dry air-stream. The beaker is placed overnight in a vacuum desiccator (containing silica gel desiccant) before weighing. Prolonged exposure of octanoic acid within a vacuum desiccator gives rise to small losses on repeated gravimetric estimation. For this reason 24 hours is suggested as a maximum period in the desiccator.

(v) Calculation. Faecal fat (g.) =

wt. residue (g.) $\times \frac{25}{20} \times \frac{\text { wt. homogenate }}{20} \times \frac{40}{14}$

(where $\frac{40}{14}$ is the factor relating the aliquot saponified to that extracted).

Composition of faecal fatty acids by gas-liquid chromatography (GI.C). From the petroleum ether extract remaining in the stoppered tube after the gravimetric determination, an aliquot containing about $0.5 \mathrm{mg}$. lipid is separated by thin-layer chromatography, and methyl esters of the non-esterified fatty acids are prepared for gas liquid chromatography separation, with precautions to avoid loss of methyl octanoate, as described by Fosbrooke and Tamir (1968).

Correspondence to Dr. June $\mathrm{K}$. Lloyd, Institute of Child Health, Guilford Street, London W.C.1. 